\title{
Genetic variation and the ability to colonise new niches in the flour beetle Tribolium castaneum (Herbst) (Coleoptera, Tenebrionidae)
}

\author{
Orna Bergerson and David Wool*
}

Department of Zoology, George S. Wise Faculty of Life Sciences, Tel Aviv University, Tel Aviv 69978, Israel

A genetically-heterogeneous synthetic strain of the flour beetle, Tribolium castaneum (Tenebrionidae) survived better than the laboratory strains used in its synthesis on 10 of 12 different diets. This advantage was not expressed in the optimal, standard wheat flour diet. Moreover, the synthetic strain survived on 12 diets, while most of the laboratory strains survived on 8 or less.

The food medium is an entire ecological habitat for flour beetles. The results thus illustrate the better colonising ability and superior potential for evolutionary success of genetically-heterogeneous populations.

\section{INTRODUCTION}

Flour beetles (Tribolium) are world-wide pests of many stored products and have lived in human grain and food stores since early historical times, so that their original diets and habitats are not known with certainty (see review in Sokoloff, 1974). Over 50 years of intensive laboratory research with these organisms, particularly in population ecology and genetics, has resulted in the production of many isolated, genetically distinct laboratory strains, inbred to varying degrees (Sokoloff 1966, 1977).

The food for Tribolium is not only a source of energy, but an entire habitat. All the developmental stages from egg to adult coexist in the food medium. Therefore the ability to survive on more diets may be interpreted as a better colonising ability and an indication of a better prospect of evolutionary success (Lewontin 1957).

The objective of the present research was to find out how well these laboratory strains survive on a range of different diets, after many generations of rearing on a standard medium (wheat flour and brewers' yeast, 100:5, in most laboratories). As a control for the effect of the limited gene pool in the laboratory strains, we created a synthetic strain by crossing together 14 different laboratory stocks, and tested it along with the parental strains.

\footnotetext{
* To whom all correspondence should be addressed.
}

\section{MATERIALS AND METHODS}

The 14 strains of Tribolium castaneum used in this study are listed in table 1 . Seven were wild-type and seven carried different morphological markers. All strains were combined in the formation of the synthetic strain (labelled S12). Pairwise crosses for this purpose were carried out over 4 generations. Virgin males and females for the crosses were obtained by separating the sexes in the pupal stage. Two hundred adults of each sex were used in each cross (reciprocal crosses were made and combined in every stage of the design). The resulting S12 was used in a long-term study which followed the present experiment (Bergerson 1985).

The strains listed in table 1, excluding paddle and $e u$, were tested together with $\mathrm{S} 12$ on the different diets (see below).

\section{EXPERIMENTAL DESIGN}

Adults from $\mathrm{S} 12$ and the 12 pure strains were allowed to oviposit for 4 days in separate jars with standard medium. To start the experiments the flour was sifted to collect the eggs and random samples of 100 eggs were counted into vials with $3 \mathrm{~g}$ of food. Three replicate samples of each strain were tested on each of the following 15 diets: standard medium, unenriched flour, pure brewers' yeast, powdered rice, ground dog biscuit pellets, 
Table 1 List of strains and some of their properties; genetic details of the mutant markers are given in Sokoloff (1966, 1977)

\begin{tabular}{|c|c|c|}
\hline $\begin{array}{l}\text { Code } \\
\text { No. }\end{array}$ & Mutant strains & Some properties \\
\hline 1 & paddle $(p d)$ & $\begin{array}{l}\text { Homozygous for the } \\
\text { sex-linked-paddle- } \\
\text { antenna allele. U.S.A. } \\
\text { origin. }\end{array}$ \\
\hline 2 & black $(b)$ & $\begin{array}{l}\text { Homozygous for } b \\
\text { (black body) allele } \\
\text { (semi dominant). } \\
\text { U.S.A. origin. }\end{array}$ \\
\hline 3 & black paddle ( $p d b b)$ & $\begin{array}{l}\text { Double homozygote for } \\
p d \text { and } b \text { (synthetic } \\
\text { strain). Israeli origin. }\end{array}$ \\
\hline 4 & pearl $(p)$ & $\begin{array}{l}\text { Homozygous for the } \\
\text { recessive pearl-eye } \\
\text { allele. U.S.A. origin. }\end{array}$ \\
\hline 5 & microcephalic $(m c)$ & $\begin{array}{l}\text { Homozygous for the } \\
\text { recessive } m c \text { allele. } \\
\text { Israeli origin (Wool } \\
\text { 1985). }\end{array}$ \\
\hline 6 & $\begin{array}{l}\text { pearl-microcephalic } \\
(p / m c)\end{array}$ & $\begin{array}{l}\text { Double homozygote for } \\
p \text { and } m c \text { (synthetic } \\
\text { strain). Israeli origin. }\end{array}$ \\
\hline 7 & Kano & $\begin{array}{l}\text { Malathion-resistant, } \\
\text { Nigerian origin. } \\
\text { (Parkin 1965). } \\
\text { Obtained from Slough, } \\
\text { England. }\end{array}$ \\
\hline 8 & $\begin{array}{l}\text { extra-irogomphi-black } \\
\quad(e u b b)\end{array}$ & $\begin{array}{l}\text { Double homozygote for } \\
\text { the incompletely- } \\
\text { penetrant } e u \text { allele } \\
\text { (Wool and Mendlinger } \\
\text { 1973) and } b \text { (synthetic } \\
\text { strain). Israeli origin. }\end{array}$ \\
\hline 9 & $C T C-12$ & $\begin{array}{l}\text { Insecticide resistant. } \\
\text { Australian origin } \\
\text { (obtained from } \\
\text { England). }\end{array}$ \\
\hline 10 & bonzo & Israeli origin. \\
\hline 11 & Berkeley & $\begin{array}{l}\text { Composite strain. } \\
\text { U.S.A. origin. }\end{array}$ \\
\hline 12 & McGill & U.S.A. origin. \\
\hline 13 & sumsum & $\begin{array}{l}\text { Israeli origin } \\
\text { (descended from a } \\
\text { single field-collected } \\
\text { fertilised female). }\end{array}$ \\
\hline 14 & solet & $\begin{array}{l}\text { Israeli origin (from a } \\
\text { field-collected sample). }\end{array}$ \\
\hline
\end{tabular}

oats, cornflour, semolina, synthetic starch (BDH), used culture medium ("concitioned" flour), shredded coconut, bread crumbs, matza meal, sesame seeds and rat-food pellets (Purina).

All vials were held in an incubator controlled at $30^{\circ} \mathrm{C}$ and 70 per cent R.H. Five weeks after the experiment began, a census was taken of all living individuals in the vials.

\section{Statistical analysis}

We were primarily interested in the effect of the difference in genetic backgrounds between the laboratory strains and the synthetic S12. Per cent survival (angular transformation) of the 13 strains on each diet were treated by single classification analysis of variance followed by an a priori (planned) comparison of S12 against the other strains (Sokal and Rohlf 1981). For illustration, we calculated for each ANOVA the minimally significant range at the 5 per cent level (MSR; Sokal and Rohlf 1981). A difference between two means (in a priori comparisons) larger than MSR is significant at $P<0.05$.

\section{RESULTS}

On three dicts-coconut, synthetic starch, and cornflour-survival of all strains was almost zero. These diets were omitted from the analysis. ANOVA on survival on all the other diets yielded significant differences among strains $(P<0.05$ at least). A priori comparisons demonstrated that on 10 of the 12 diets, S12 survived better than the mean of the other strains, -in 6 comparisons significantly so (fig. 1 ).

In some strains and diets survival was as low as 1-2 per cent. These values may be ecologically meaningless. If we take arbitrarily 5 per cent survival as the lower limit, we find that $\mathrm{S} 12$ survived on 12 diets. Two laboratory strains were as good: solet (12) and sumsum (11). Eight of the pure strains survived on eight diets or less. CSbb survived on 4 diets only of the 15 offered.

Another aspect of the survival analysis is the comparison of S12 to the other strains within each diet. (table 2). The table shows that on two dietsstandard medium and unenriched flour (same as the first but without adding 5 per cent yeast), S12 had no advantage over the other strains-in fact, six strains of the 12 survived better than the synthetic strain. The relaiive advantage of $\mathrm{S} 12$ is expressed in the diets most dissimilar from the standard: on yeast, bread crumbs, oats and synthetic starch, no other strains survived better than $\mathrm{S} 12$, and on matza meal and conditioned flour it was surpassed by only one strain (sumsum).

\section{DISCUSSION}

Lewontin (1957) suggested that in order to compare the adaptive ability of populations, or estimate the potential of a population to survive a 


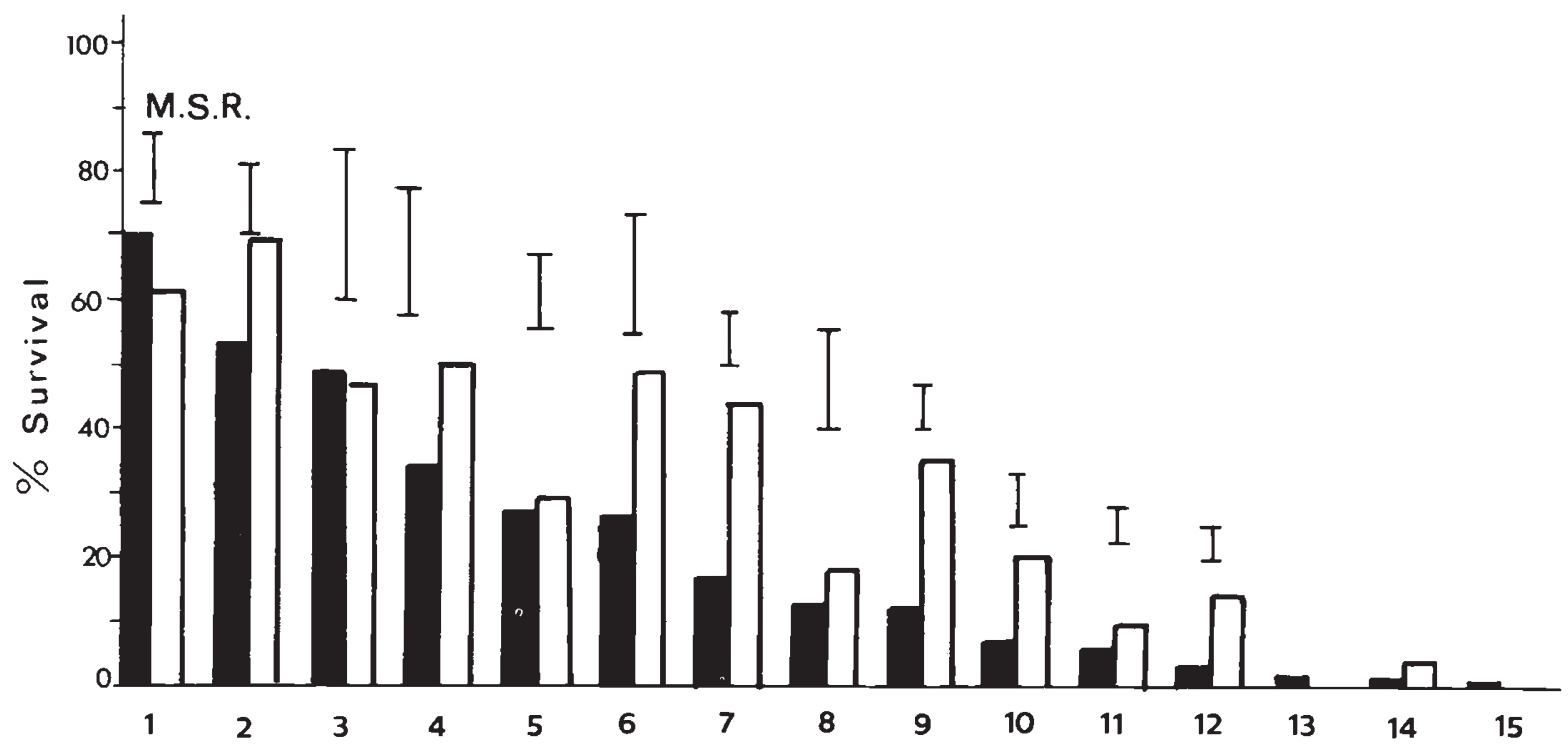

Figure 1 Mean percent survival of the synthetic strain $\mathrm{S} 12(n=3$, hollow bars $)$ and the mean of all 12 pure strains $(n=3 \times 12=36$, black bars) on each of 15 diets. MSR (=minimally significant range) illustrates the smaliest difference between two means (in each diet) which is significant at the 5 per cent level. 1) standard medium, 2) rat food, 3) unenriched flour, 4) powdered rice, 5) semolina, 6) oats, 7) dog food, 8) "conditioned" flour, 9) brewer's yeast, 10) matza meal, 11) sesame seeds, 12) breadcrumbs, 13) coconut, 14) synthetic starch, 15) cornflour.

Table 2 Survival of $T$. castaneum laboratory strains on 12 diets, compared with $\mathrm{S} 12$. Average of 3 replicates per strain (100 eggs per sample)

\begin{tabular}{|c|c|c|}
\hline Diet & $\begin{array}{l}\% \text { Survival } \\
\text { of S12 }\end{array}$ & $\begin{array}{l}\text { Strains with better survival } \\
\text { on the same diet }(\%)\end{array}$ \\
\hline Standard medium & $61 \cdot 3$ & $\begin{array}{l}\text { sumsum }(85 \cdot 3) \text {, csbb } \\
(75 \cdot 7) \text {, pearl }(85 \cdot 3) \text { Kano } \\
(73 \cdot 0) \text {, solet }(70 \cdot 0) \text {, } \\
\text { Berkeley }(86 \cdot 0)\end{array}$ \\
\hline Unenriched flour & $46 \cdot 7$ & $\begin{array}{l}\text { sumsum }(72 \cdot 7) \text {, pearl } \\
(63 \cdot 7) \text {, McGill }(67 \cdot 0) \\
\text { pdbb }(59 \cdot 0) \text {, solet }(48 \cdot 7) \text {, } \\
\text { Berkeley }(59 \cdot 3)\end{array}$ \\
\hline Rat food & $69 \cdot 3$ & $\begin{array}{l}\text { sumsum }(80 \cdot 0), \text { McGill } \\
(72 \cdot 0), \text { pdbb }(72 \cdot 0)\end{array}$ \\
\hline Semolina & $29 \cdot 0$ & $\begin{array}{l}\text { sumsum }(58 \cdot 0) \text {, solet } \\
(44 \cdot 7), \text { Berkeley }(50 \cdot 3)\end{array}$ \\
\hline Powdered rice & $50 \cdot 0$ & CTC $(55 \cdot 7)$, pearl $(64 \cdot 0)$ \\
\hline Dog food & $44 \cdot 3$ & $\begin{array}{l}\text { sumsum }(51 \cdot 7) \text {, solet } \\
(50 \cdot 3)\end{array}$ \\
\hline Conditioned flour & $18 \cdot 7$ & sumsum $(25 \cdot 7)$ \\
\hline Matza meal & $15 \cdot 0$ & sumsum $(27 \cdot 0)$ \\
\hline Brewers' yeast & $35 \cdot 0$ & None \\
\hline Bread crumbs & $14 \cdot 7$ & None \\
\hline Oats & $49 \cdot 3$ & None \\
\hline Synthetic starch & 3.7 & None \\
\hline
\end{tabular}

long period of time in the future (evolutionary success), one may measure its ability to survive at present in a wide variety of environmental conditions.
In the present experiment we show that $\mathrm{S} 12$, synthesised from 14 different genetic backgrounds, was able to survive in more food media than the laboratory strains used in its synthesis. For flour beetles, the food medium is not only a source of nourishment but an entire habitat. Therefore, we are justified in saying that S12 colonised successfully more ecological niches than the laboratory strains. This is in line with the niche width-genetic variation hypothesis (Van Valen (1965). Some cases to the contrary have been reported (e.g., McCracken and Selander 1980; Selander and Kaufman 1973).

S12 was superior in survival to most or all other strains on all diets except the standard medium and wheat flour. This suggests that new genetic combinations were formed in the synthetic strain which could exploit new resources when they became available. One explanation for the higher population size of genetically heterogeneous populations compared with populations with a more limited genetic background (e.g., Sokal and Sonleitner, 1968) may be that different genotypes use different sub-niches so that competition among them is minimized. Another possibility is "genetic facilitation" among genotypes (Lewontin 1955; Sokal and Huber 1963; Bryant 1969). A third mechanism, which could explain the success of our synthetic strain in comparison to the pure 
strains is related to developmental homeostasis (Lerner 1954): individuals in the synthetic strain most probably were heterozygous at more loci than individuals of the pure strains. The resulting physiological flexibility may have enabled them to survive better than pure-strain individuals, in particular under conditions less optimal than those in the standard medium.

Two strains, "solet" and "sumsum" stand out as equal to or sometimes better than $\mathrm{S} 12$ in survival. Solet is a wild type strain collected in a warehouse some 5 years ago. It has been reared in the laboratory a much shorter period than the other strains. It is possible that it retained more genetic variation than the mutant strains. Waterhouse and Nowosielski-Slepowron (1965) reported that a field-collected population of another flour beetle (gen. Cathartus) was more resistant to a wider range of environmental conditions than laboratory populations of the same species. "Sumsum"another recently collected strain (1978) —was started by just one fertilised female, so its original genetic background must have been limited. Yet its ability to colonise different diets was no different than S12. (Unfortunately this strain was lost in 1982).

The black laboratory strain survived in only 4 of 15 foods, and on those its average per cent survival was only $22.2 \pm 9.25$ (the strain survives very well on the standard medium). The $b$ mutation itself does not affect the fitness of individuals and changes in its frequency are apparently caused by selection on other linked genes (Stam 1975).

This experiment demonstrates the importance of genetic variation for evolutionary flexibility and success and for colonising ability. The idea itself is not new, but convincing data are not abundant. We believe that evolutionary theories should be tested periodically as a check for possible flaws and as a means of accumulating supporting evidence.

\section{REFERENCES}

BERGERSON, O. 1985. The process of adaptation of the flour beetle Tribolium to new environments, as a model of an evolutionary process. Ph.D. dissertation, Tel Aviv University (in Hebrew, English summary).

BRYANT, E. H. 1969. The fates of immatures in mixtures of two housefly strains. Ecology, 50, 1049-1069.

DAWSON, P. S. AND RIDDLE, R. A. 1983. Genetic variation, environmental heterogeneity and evolutionary stability. In Population Biology: Retrospect and Prospect. King, C. E. and Dawson, P. S. (eds.) Columbia University Press, pp. $147-170$.

LERNER, I. M. 1954. Genetic Homeostasis. John Wiley \& Sons, Inc., New York.

LEWONTIN, R. C. 1955. The effect of population density and composition on viability of Drosophila melanogaster. Evolution, 9, 27-41.

LEWONTIN, R. C. 1957. The adaptations of populations to varying environments. Cold Spring Harbor Symp. Quant. Biol., 22, 395-407.

MCCRACKEN, G. F. AND SELANDER, R. K. 1980. Self-fertilization and monogenic strains in natural populations of terrestrial slugs. Proc. Natl. Acad. Sci. USA, 77, 684-688.

PARKIN, E. A. 1965. The onset of insecticide resistance among field populations of stored-products insects. J. Stored Prod. Res., 1, 3-8.

SELANDER, R. K. AND KAUFMAN, D. W. 1973. Self-fertilization and genetic population structure in a colonizing land snail. Proc. Natl. Acad. Sci. USA, 70, 1186-1190.

SOKAL, R. R. AND HUBER, I. 1963. Competition among genotypes in Tribolium castaneum at varying densities and gene frequencies (the sooty locus). Amer. Natur., 47, 169 184.

SOKAL, R. R. AND ROHLF, F. J. 1981. Biometry. 2nd ed. Freeman \& Co., New York.

SOKAL, R. R. AND SONLEITNER, F. J. 1968. The ecology of selection in hybrid populations of Tribolium castaneum. Ecological Monographs, 38, 345-379.

SOKOLOFF, A. 1966. The genetics of Tribolium and related species. Academic Press, New York and London.

SOKOLOFF, A. 1974. The biology of Tribolium. Vol. II. Oxford, Clarendon Press.

SOKOLOFF, A. 1977. The biology of Tribolium, Vol. III. Oxford, Clarendon Press.

STAM, P. 1975. Linkage disequilibrium causing selection at a neutral locus in pooled Tribolium populations. Heredity, $34,29-38$.

VAN VALEN, L. 1965. Morphological variation and width of ecological niche. Amer. Natur., 98, 377-390.

WATERHOUSE, F. L. AND NOWOSIELSKI-SLEPOWRON, B. J. A 1965. Differences between identically reared laboratory and field stocks of the flour beetle Cathartus quadricollis Guer. Proc. XII. Int. Congr. Ent. p. 664-665.

WOOL, D. AND MENDLINGER, S. 1973. The eu mutant of the flour beetle Tribolium castaneum (Herbst). Environmental and genetic effects on penetrance. Genetica, 44, 496-504.

wOOL, D. 1985. Blind flour beetles: variable eye phenotypes in the microcephalic $(m c)$ mutant of Tribolium castaneum (Coleoptera, Tenebrionidae). Isr. J. Entomol. 19, 201-210. 